\title{
The Power of Teamwork: JGI Ergonomics Program
}

Christine Naca, Ira Janowitz, Stephen Franaszek, Ray Turner, Susan Lucas ....and the JGI Ergo Working Group
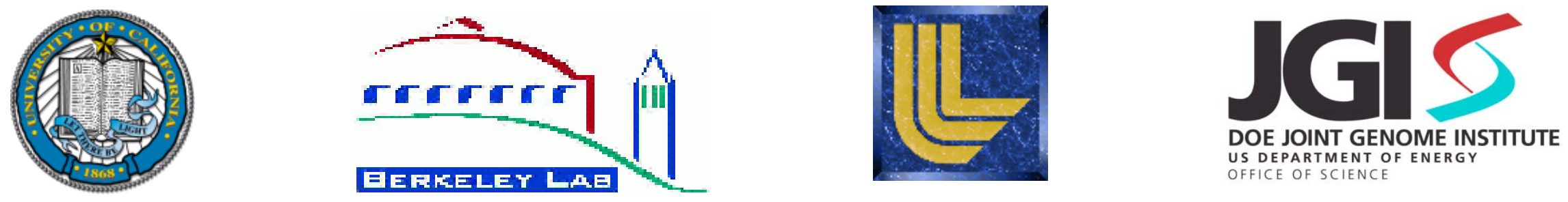


\section{Overview}

- Description of the JGI

- Review of Production Tasks

- JGI Ergonomics Program

- Ergo Methodology 


\section{DOE Joint Genome Institute}

- 250 Staff: $30 \%$ LLNL and $70 \%$ LBNL

- Mix of research and manufacturing work

-Integrated Safety Management (ISM)

- Stephen Franaszek (LBNL)

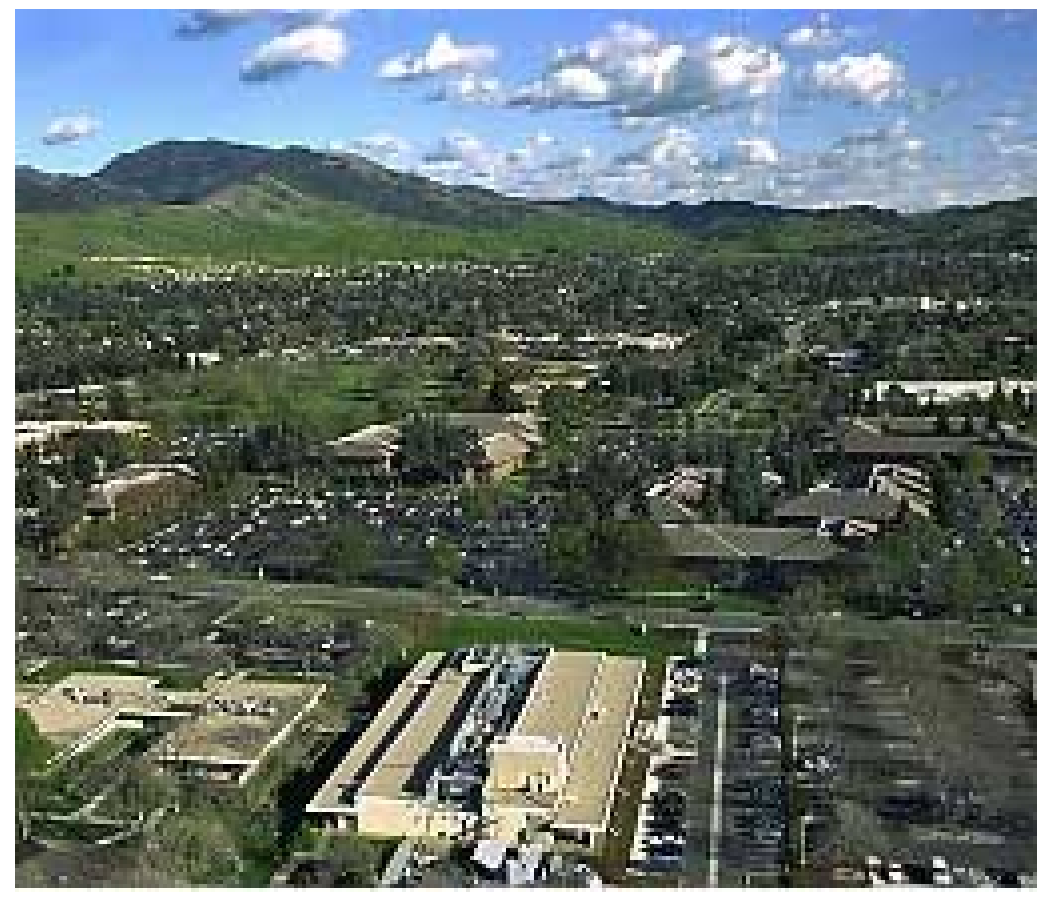

Walnut Creek, CA 


\section{Office \& Manufacturing Work Environments}

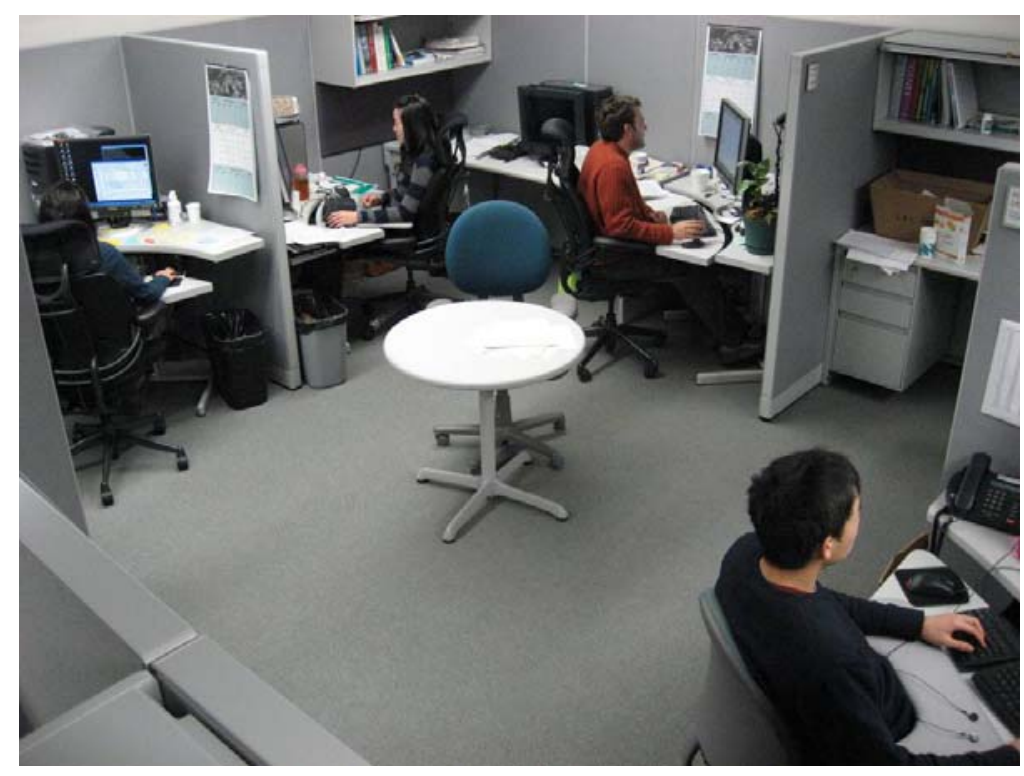

$60 \%$ staff in computerintensive office settings

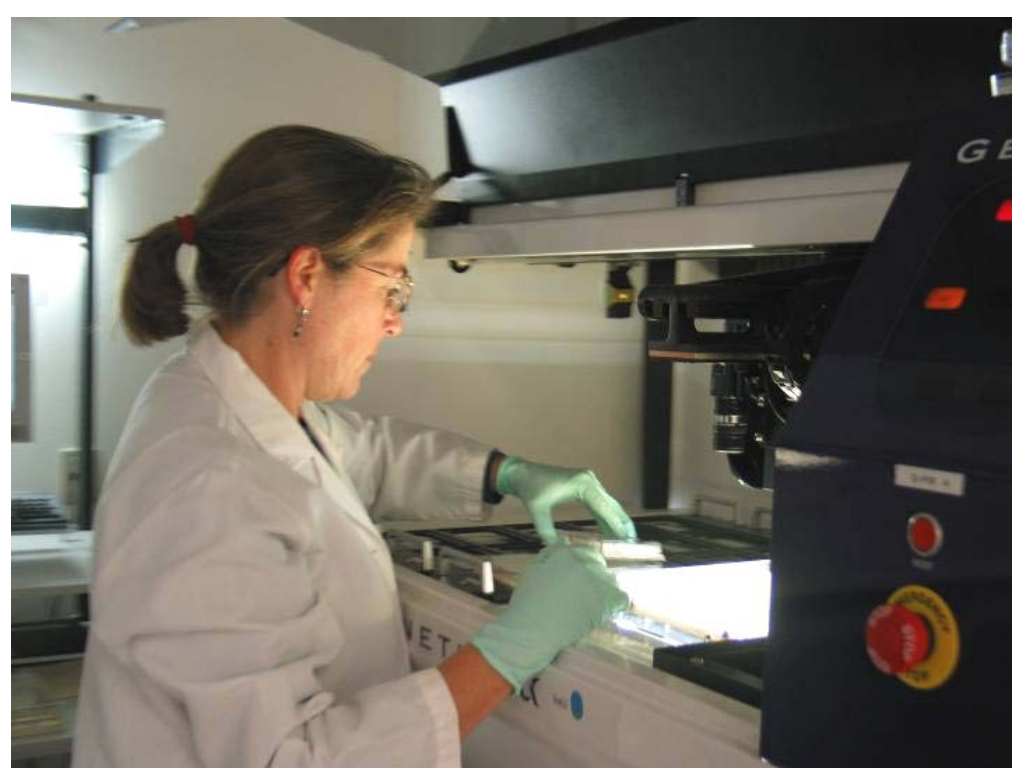

$40 \%$ staff in hand-intensive production tasks (2 shifts) 


\section{JGI Manufacturing Work Environment}
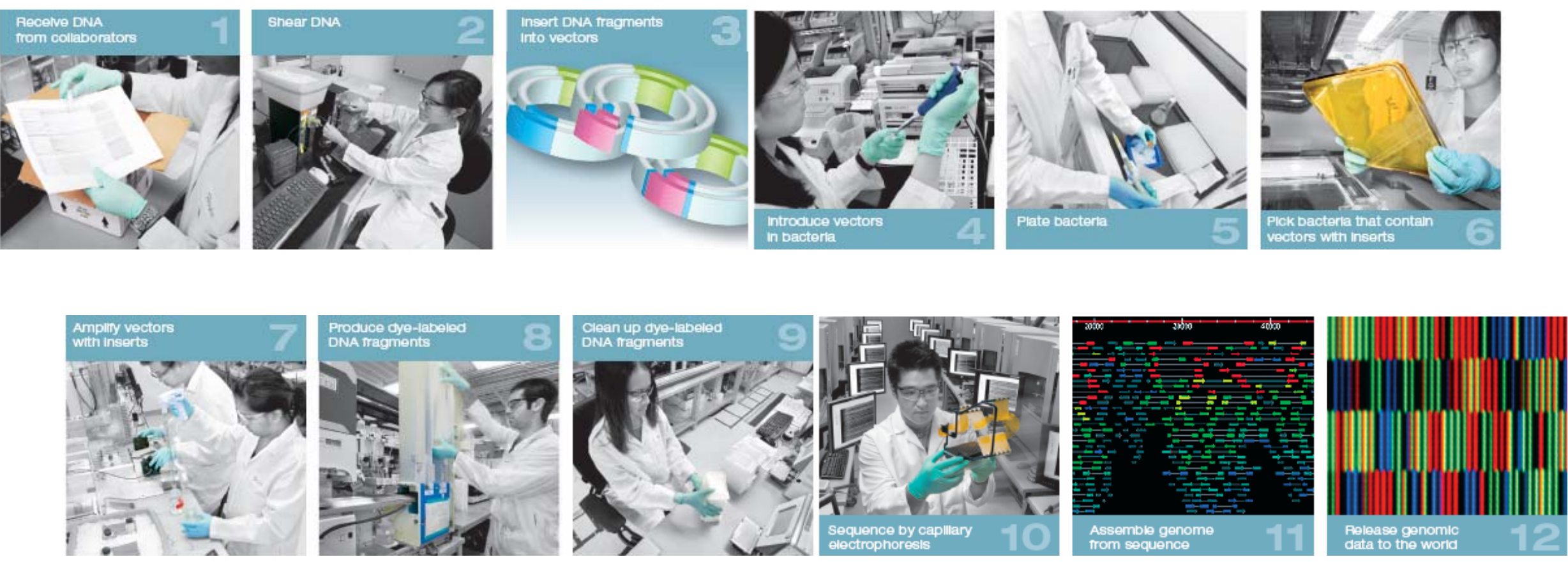

- $40 \%$ of the staff make up the manufacturing work environment

- High throughput laboratory manufacturing

- Hand-intensive repetitive tasks

- 32 people, 2 shifts/day 


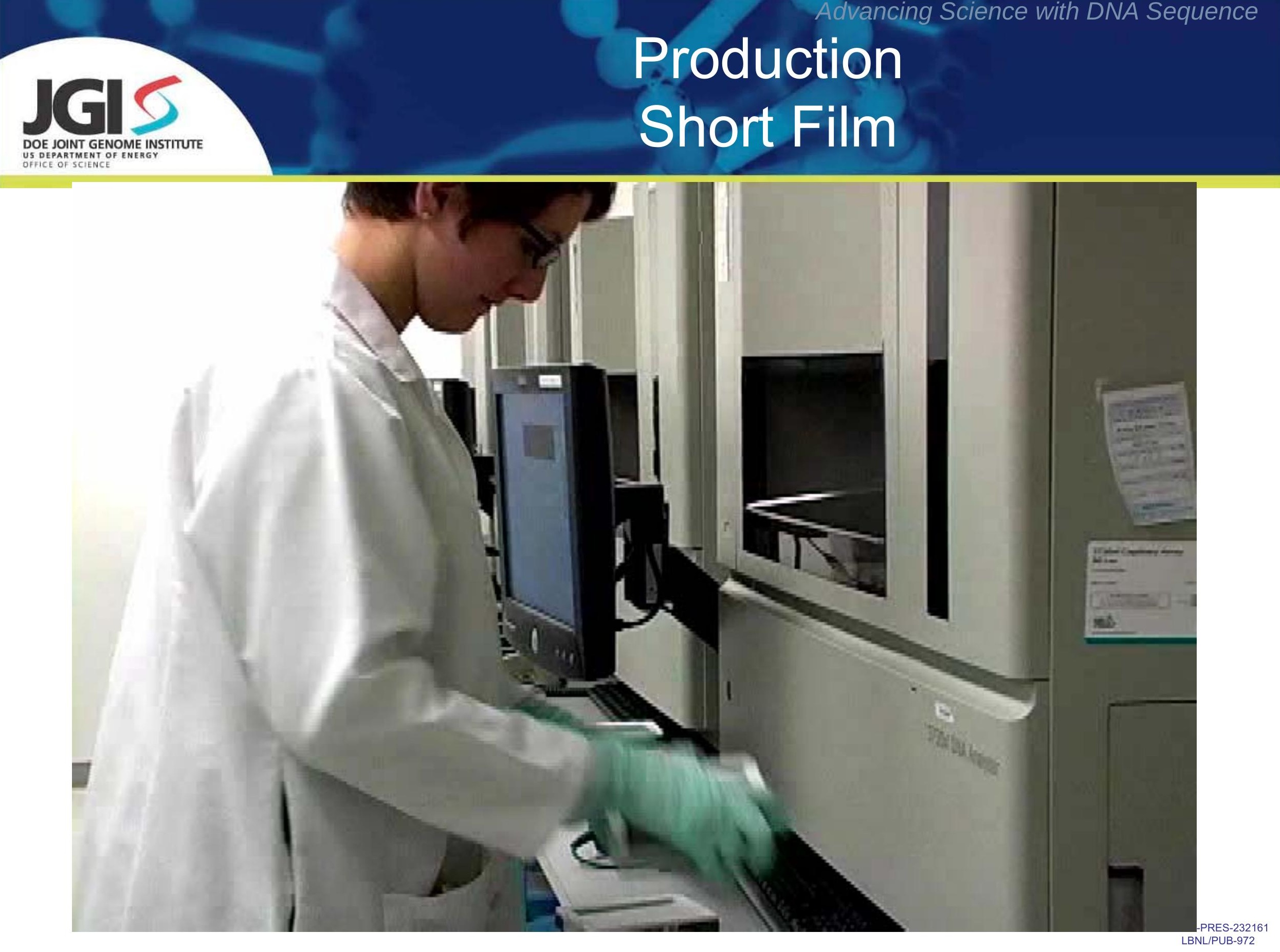




\section{Root Causes of Ergonomic Injuries}

- Equipment/instruments designed for small batches/small lab use now being used for high throughput operation

- Culture:

- Understanding Efficiency vs. Speed

- High force finger-intensive tasks 


\section{History of Ergonomics at JGI}

\section{(May 2005-Current)}

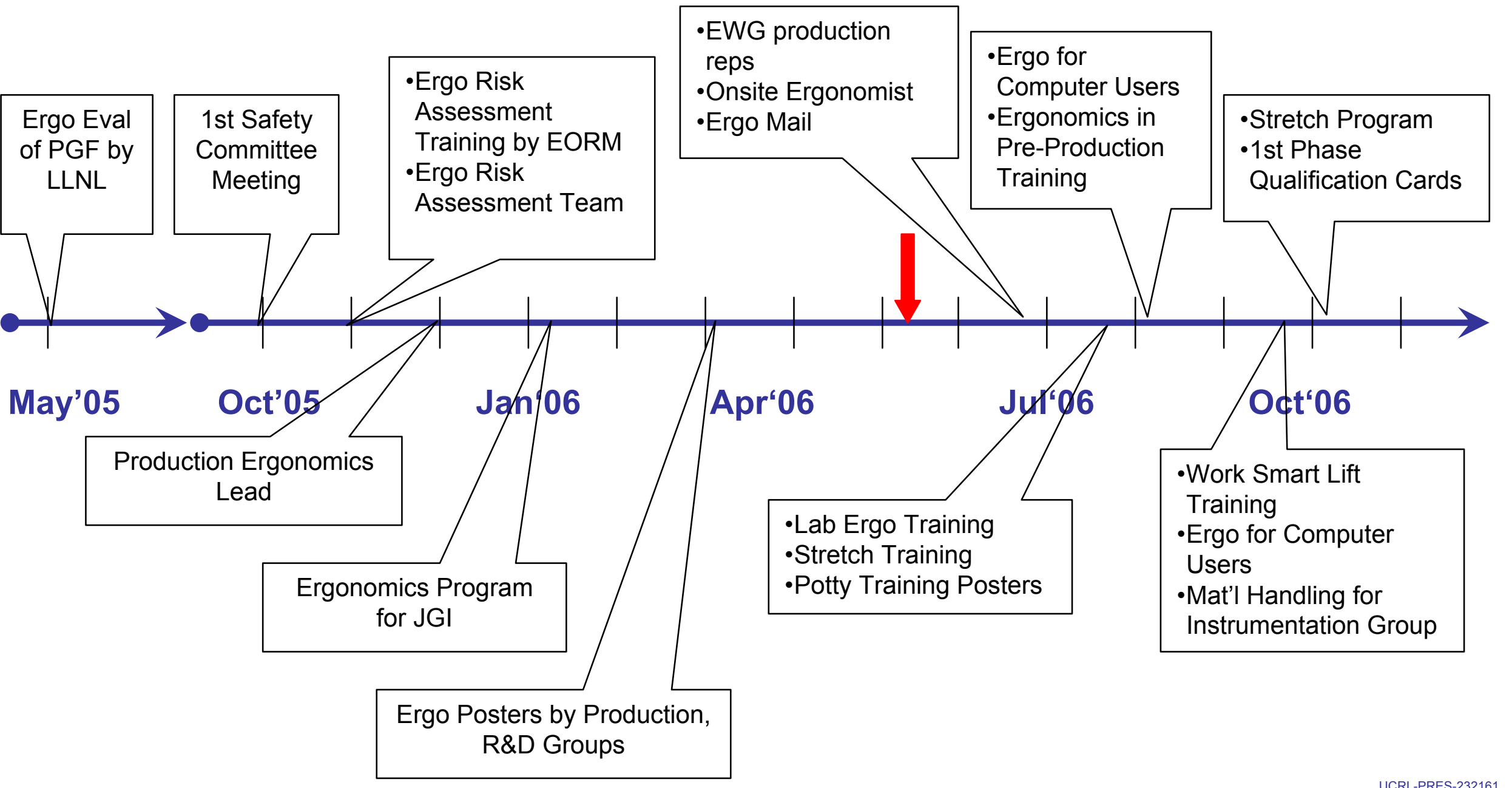




\section{Managing Ergonomics Team Effort}

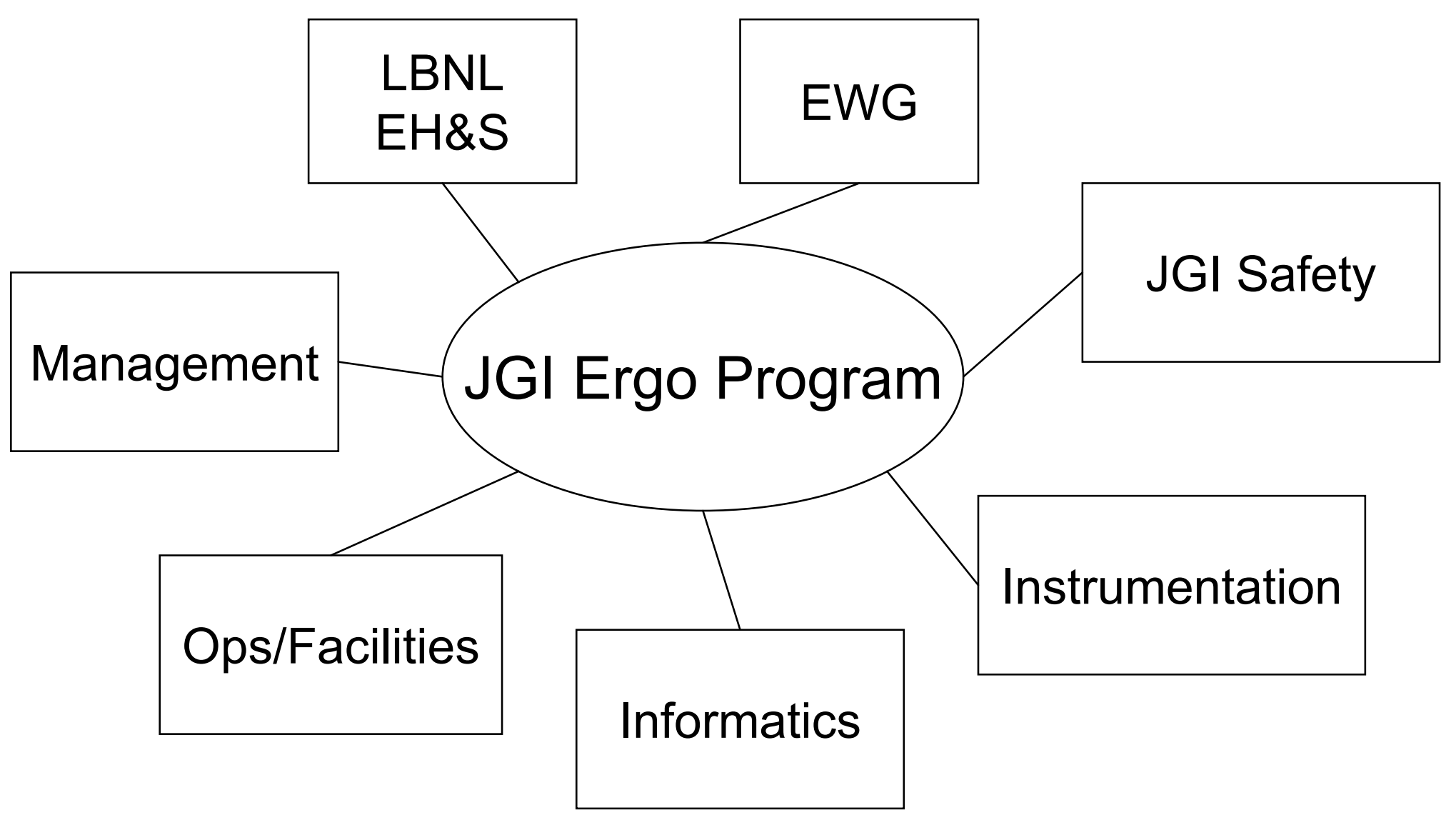




\section{Engaging the Staff}

\section{Ergonomics Working Group}

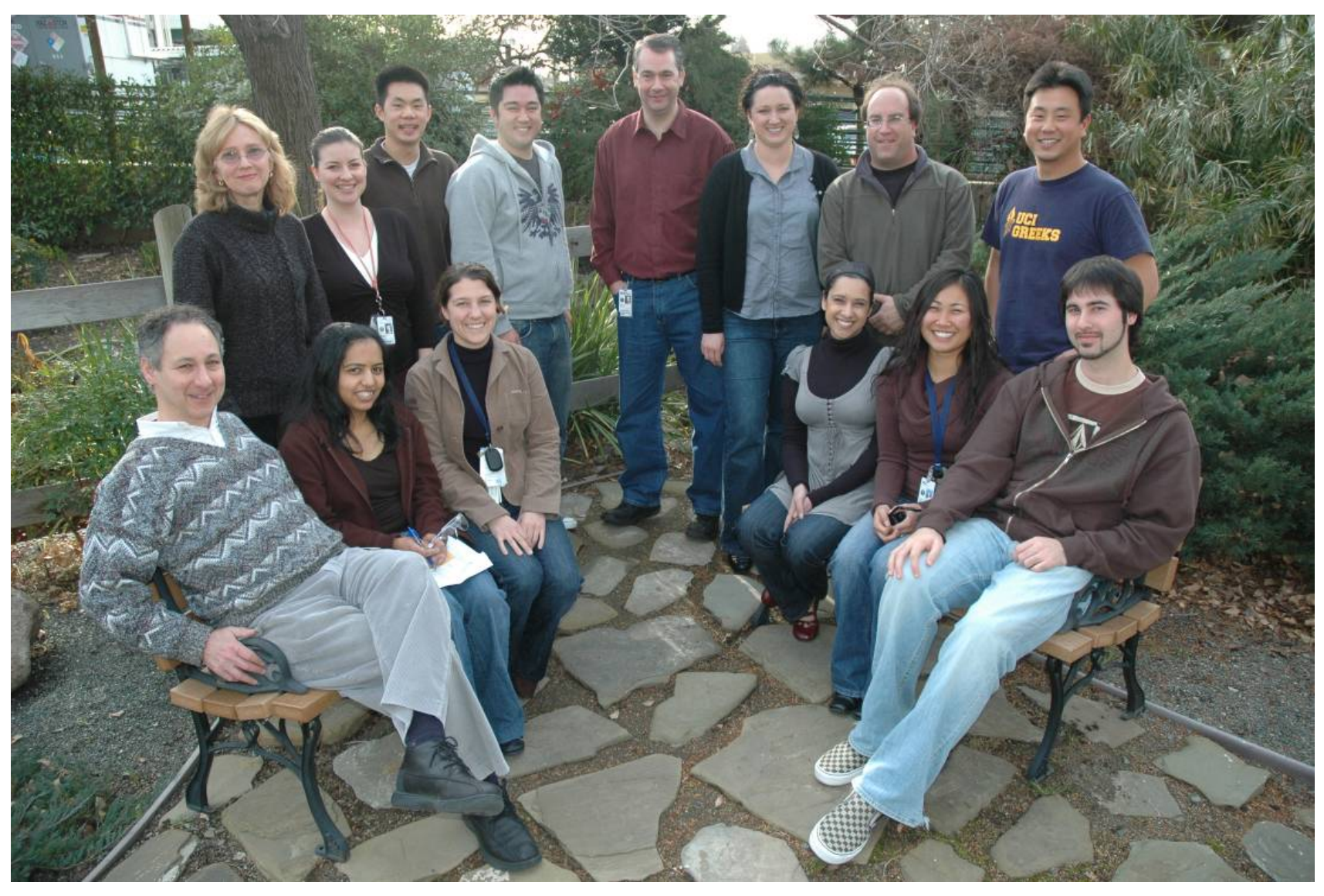




\section{Current Ergo Project Status}

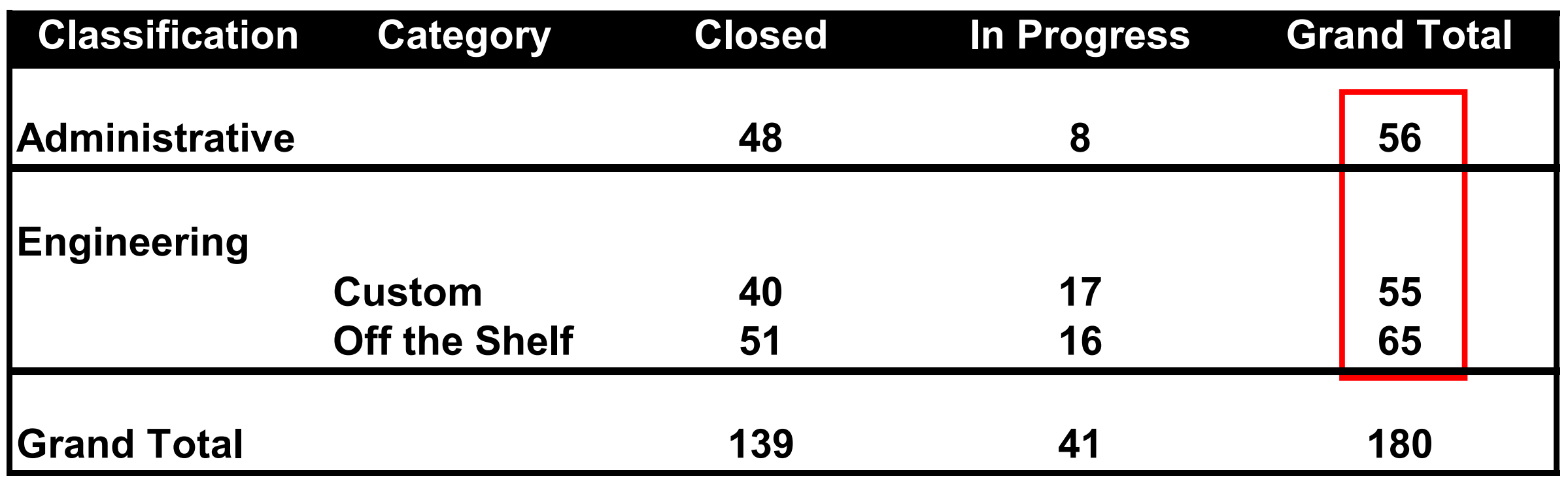

\# Ergo Projects by Classification 


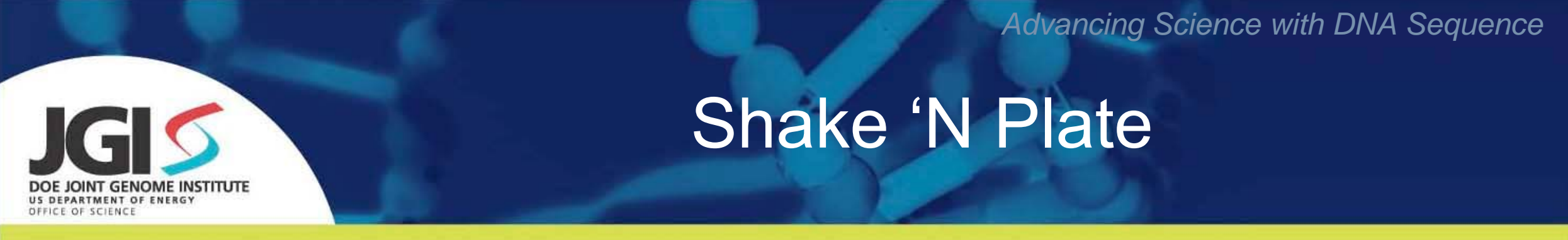

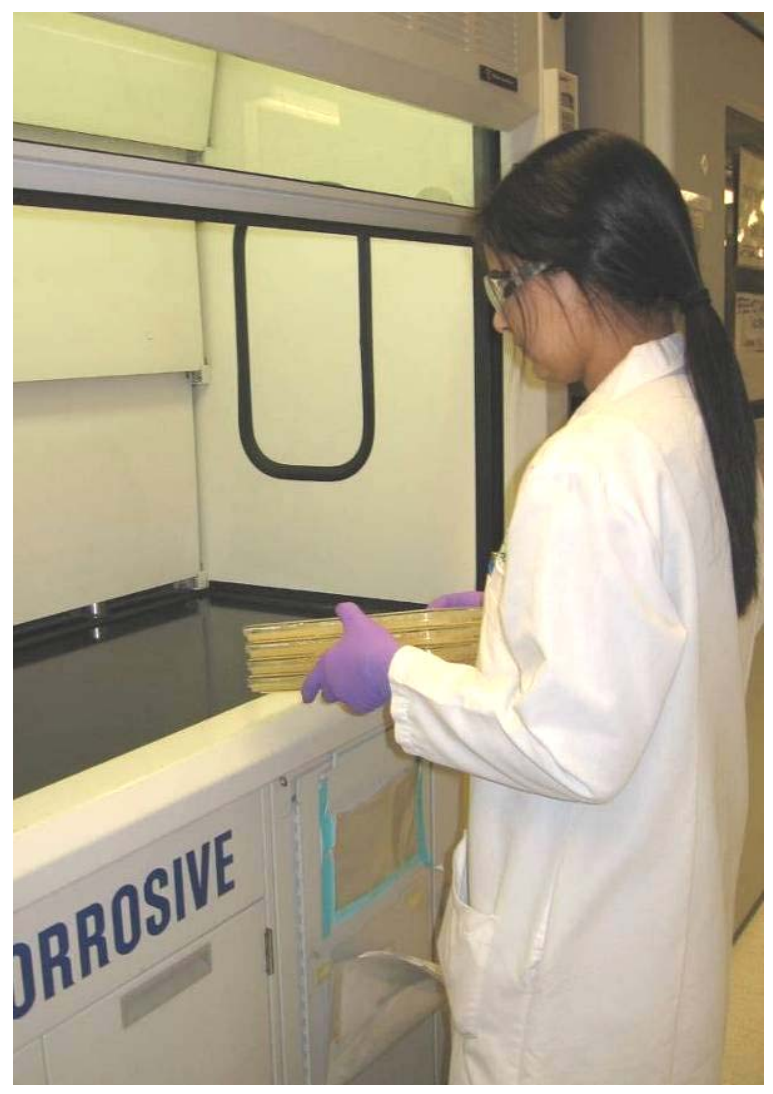

Before

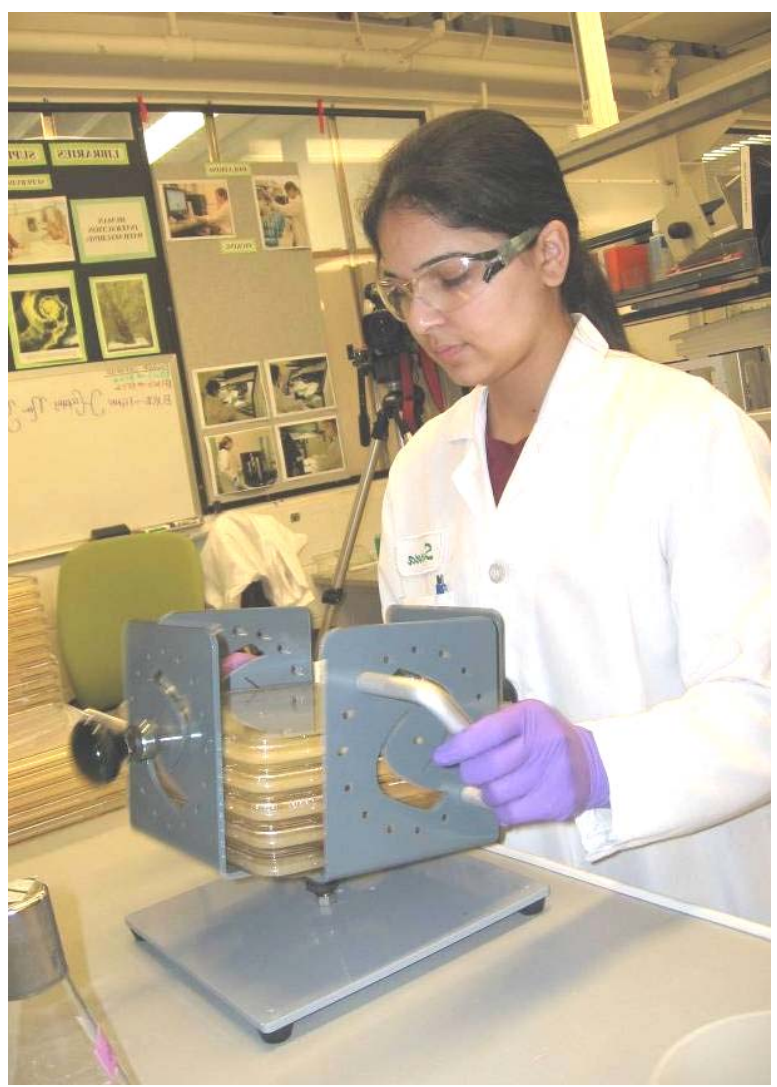

After
Administrative:

- Leg Room for seated option Off the Shelf:

- Lighter plates

-Anti-fatigue Mat

Engineering (custom):

-Fixture to hold the plates

Increased Productivity:

$\cdot 25 \% \uparrow$ throughput 
Advancing Science with DNA Sequence

JGIS Ergo Cup 2007 Winners

\section{"Team Driven Workplace Solutions"}
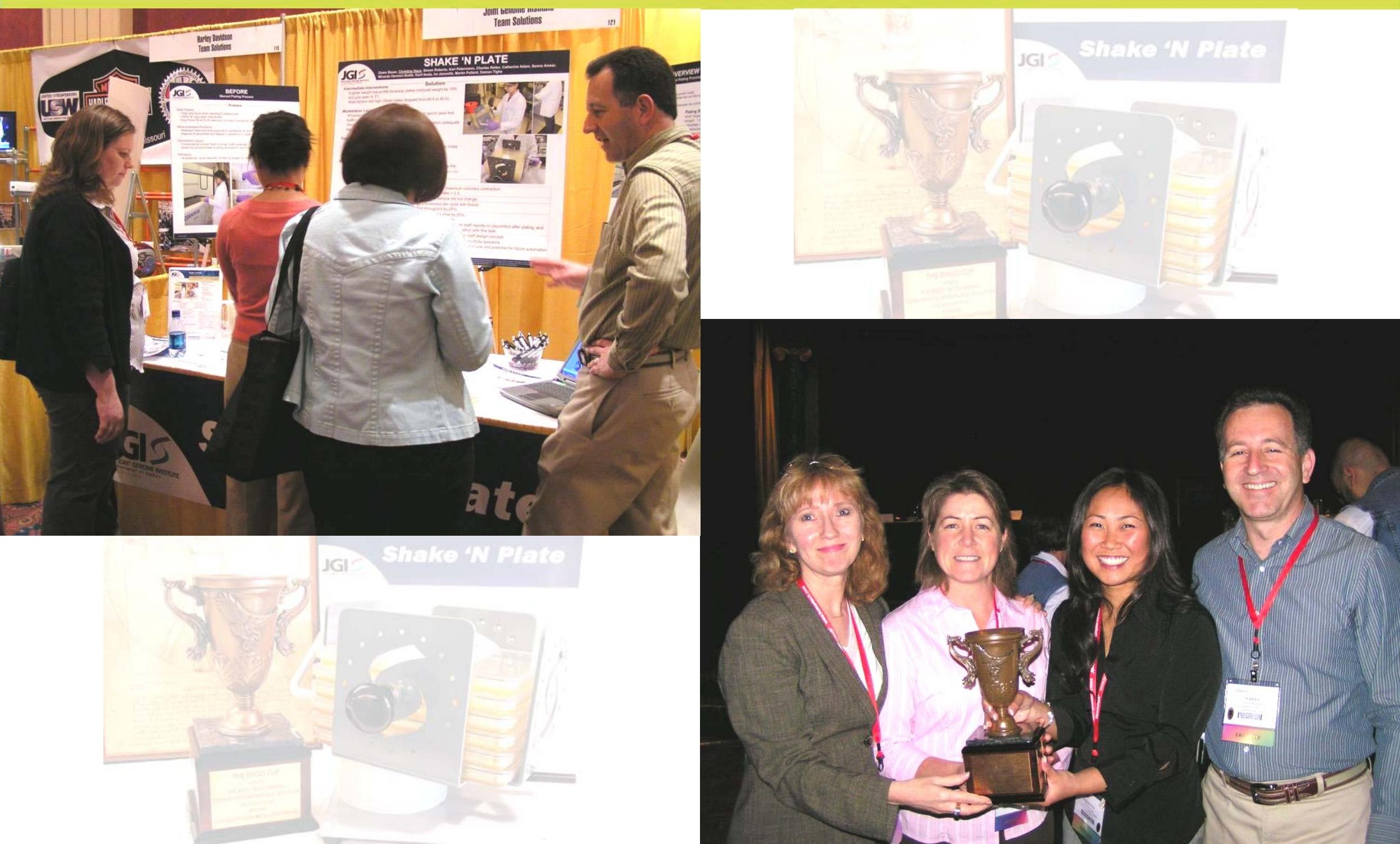


\section{JGIS \\ Top 3 High Risk Factor Tasks}

\section{Thermal Cycler Loading}
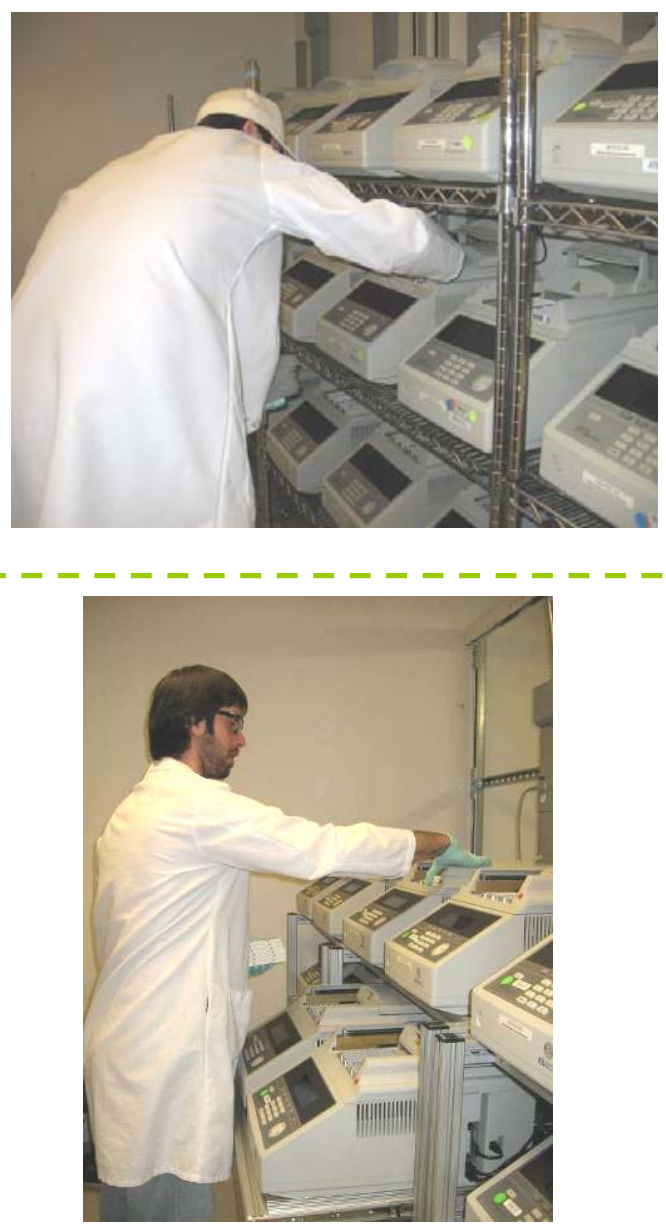

Peeling Seals
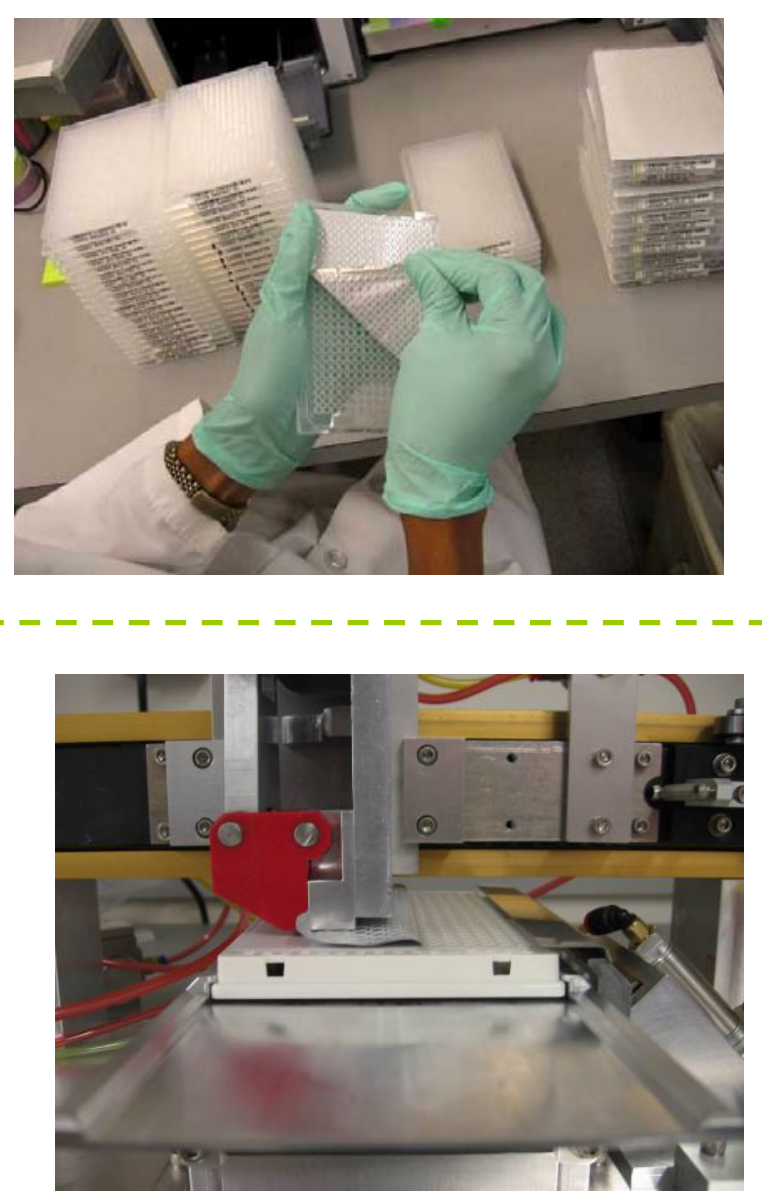

Freezer Rack Lifting
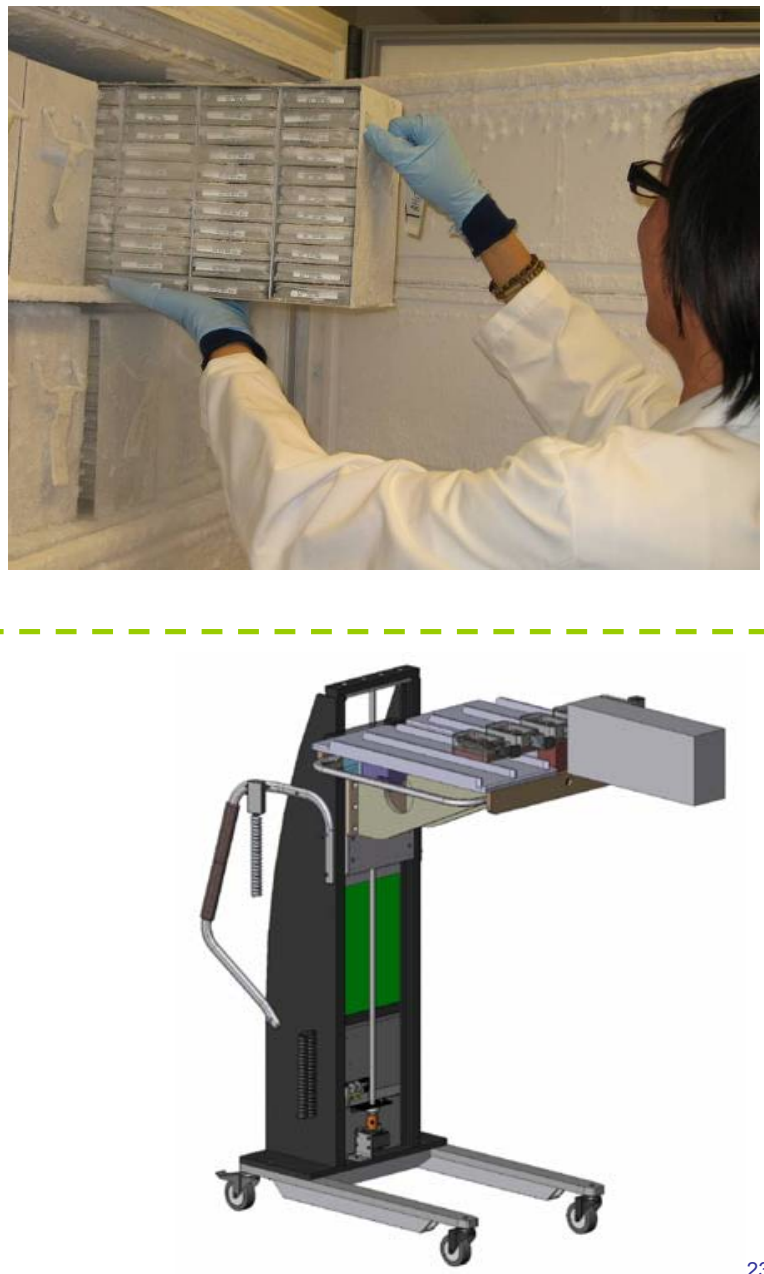


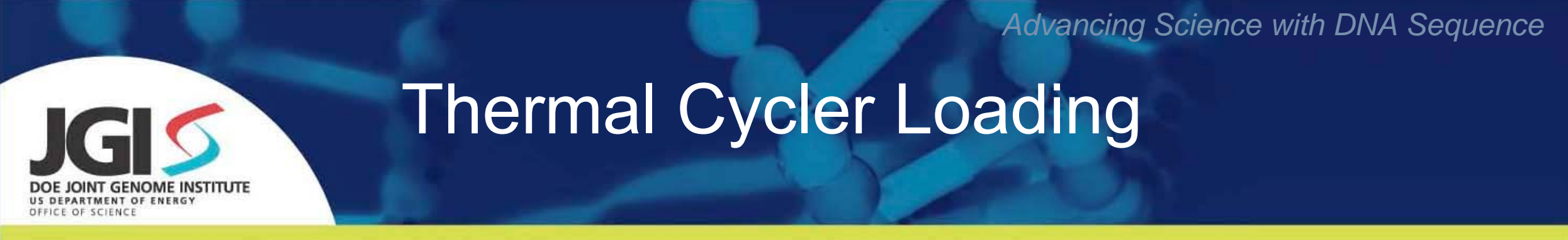

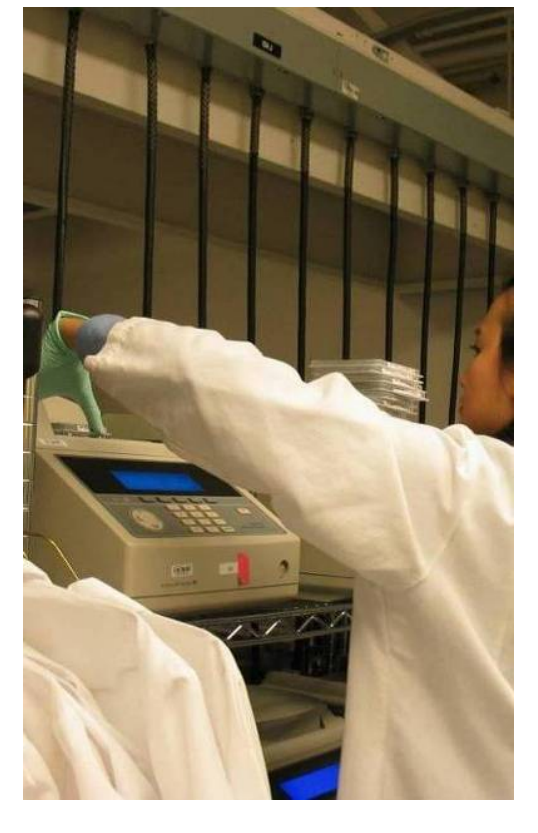

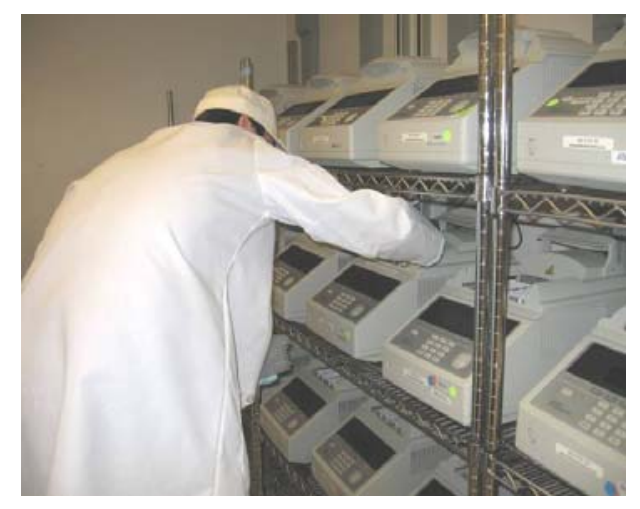

Before
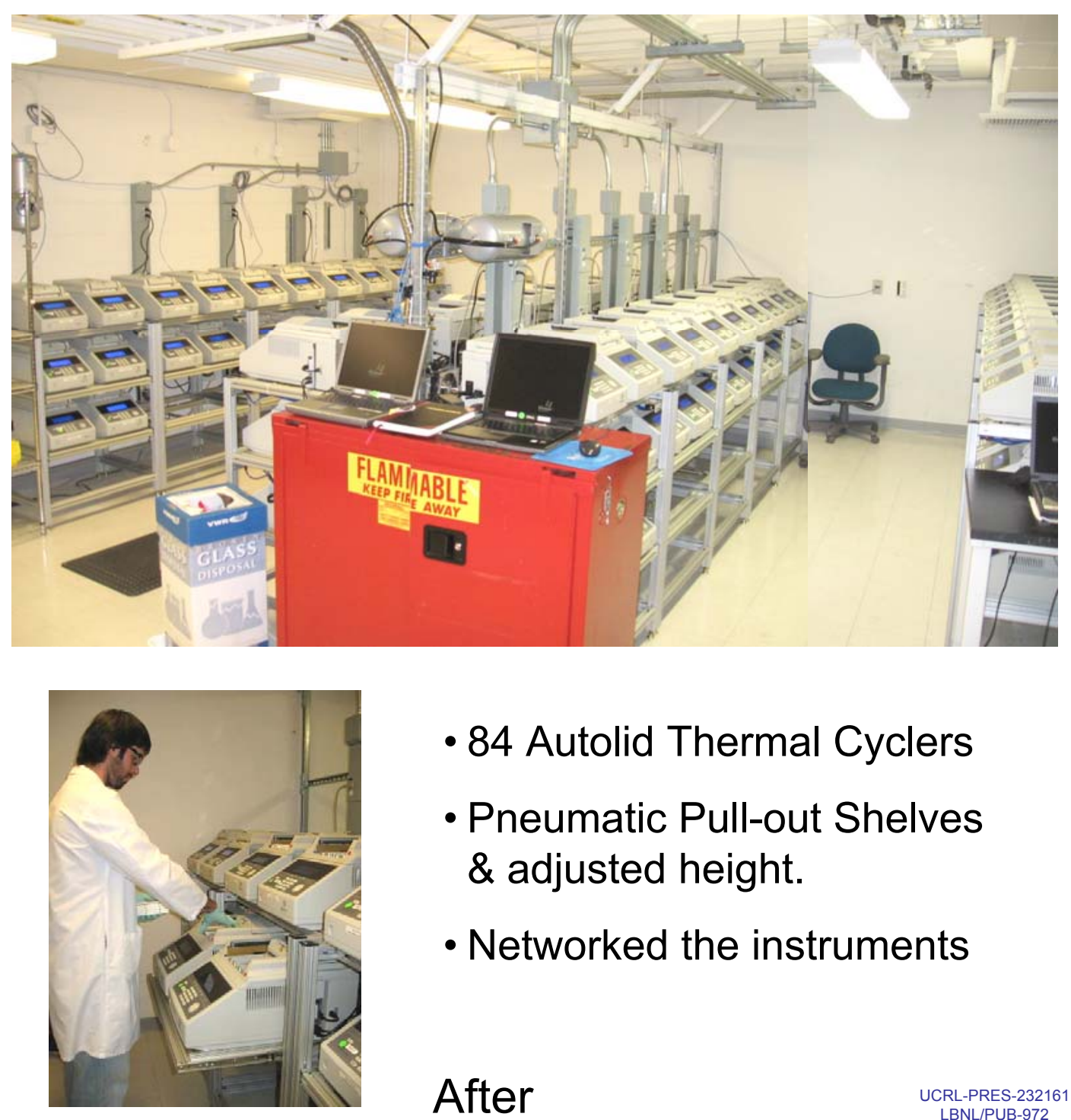

- 84 Autolid Thermal Cyclers

- Pneumatic Pull-out Shelves $\&$ adjusted height.

- Networked the instruments

After 


\section{Peeling Seals}

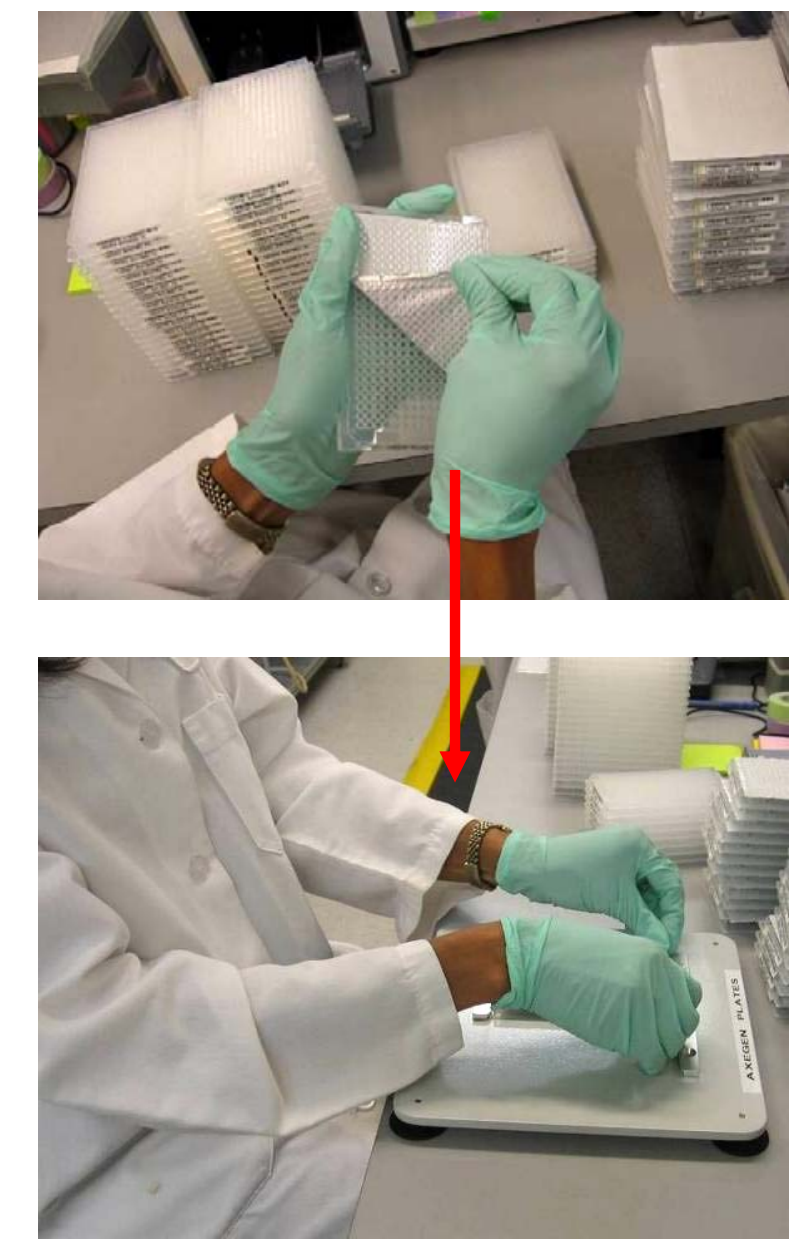

Before
-Plate Fixture to hold plates down freeing up both hands to peel

-Ergo Pliers to eliminate the pinch grip while peeling -Continual Flow eliminates $90 \%$ of foil seal peeling -LBNL custom automated peeler

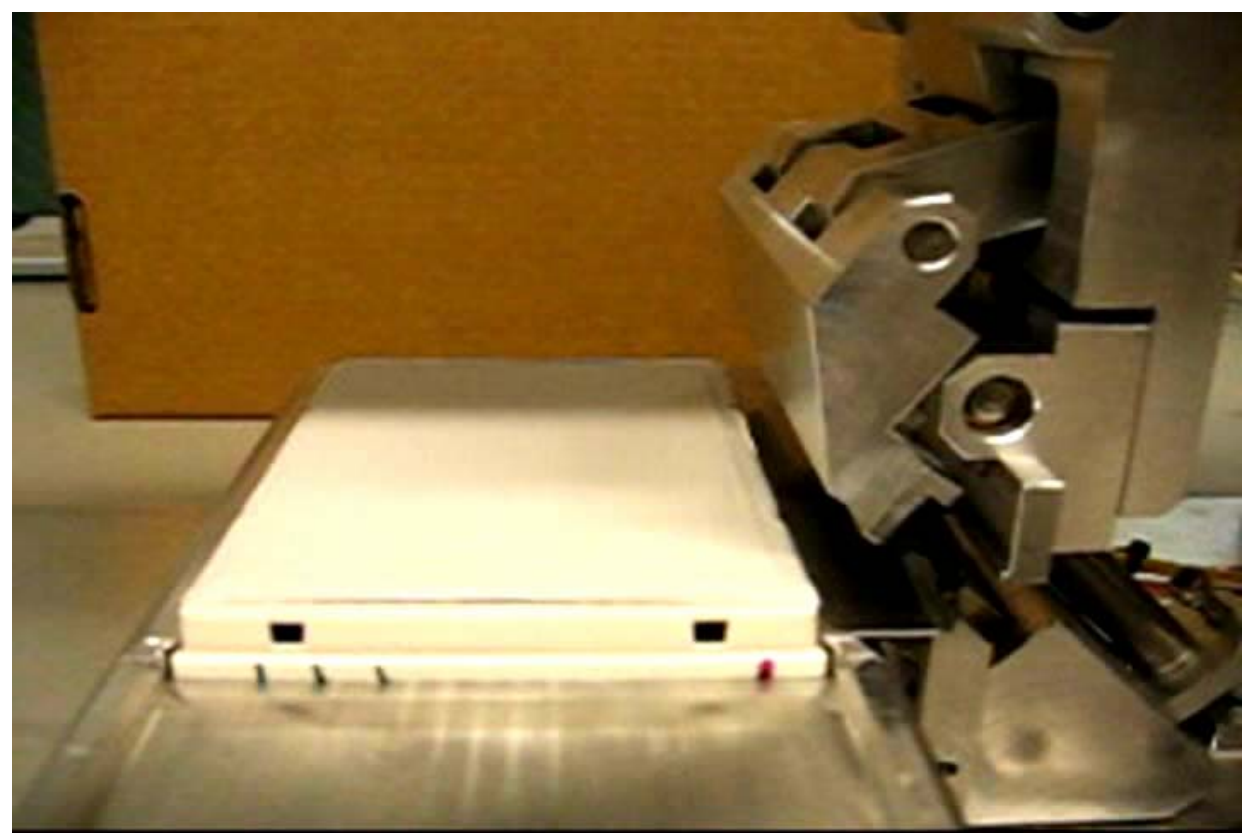

After 


\section{Freezer Rack Lifting}

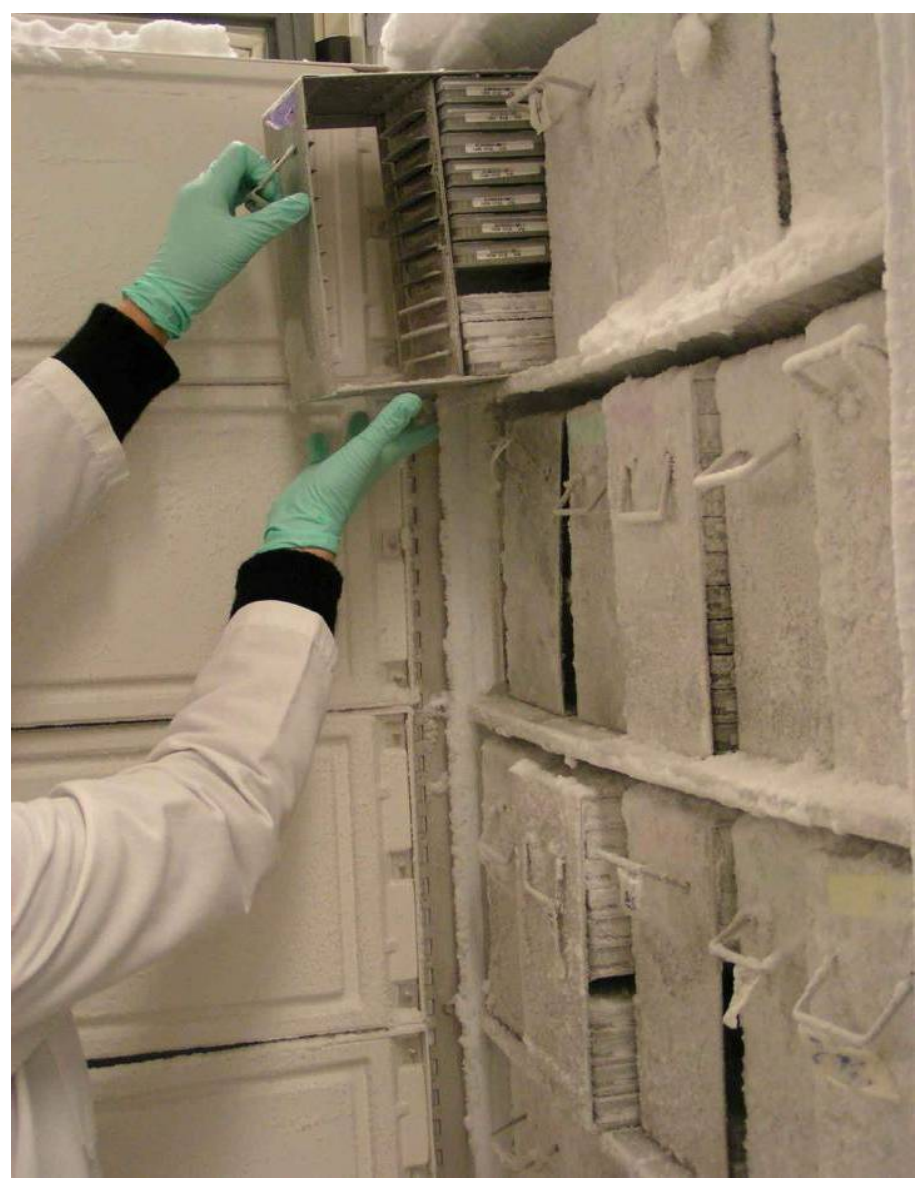

Height adjustable push/pull cart

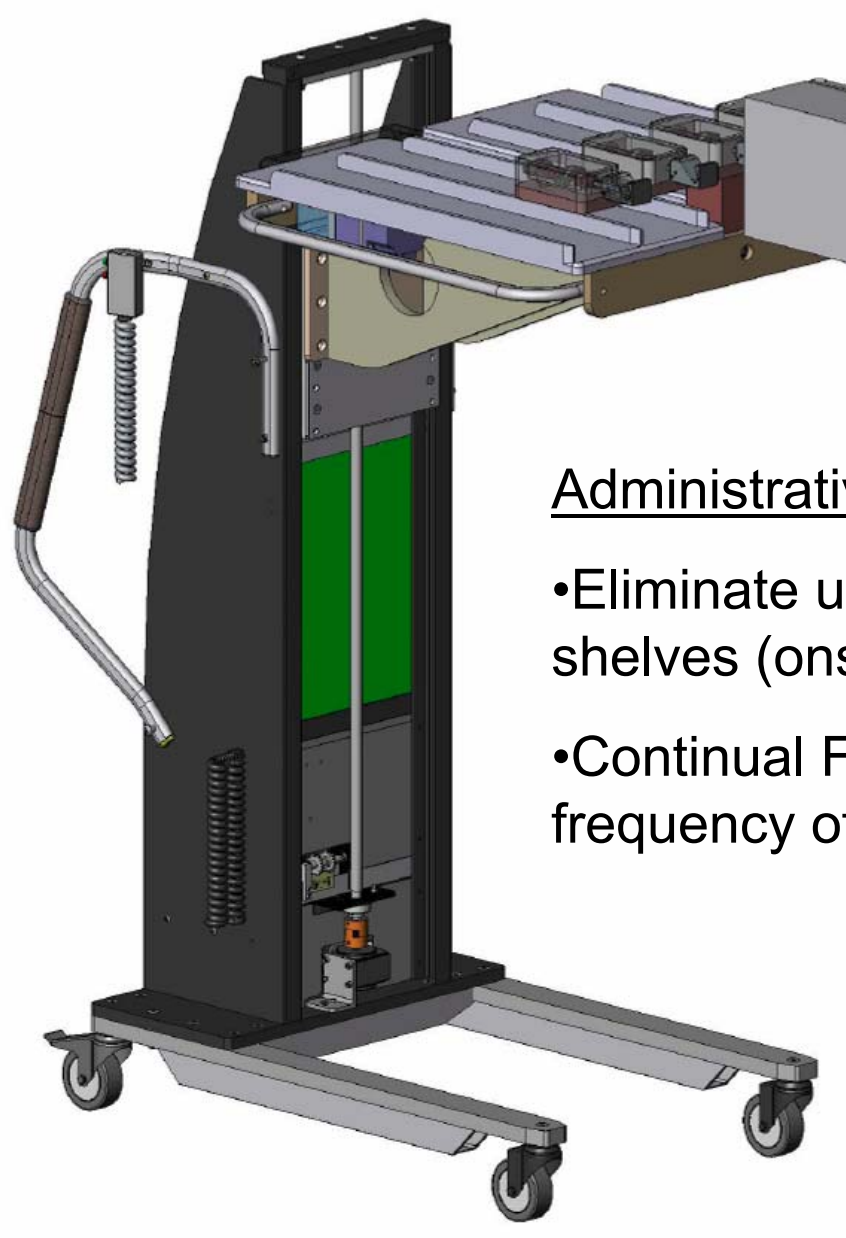

Before

After 


\section{JGIS Production Wide Ergo Improvements}

Height-Adjustable \& Custom Designed Tables
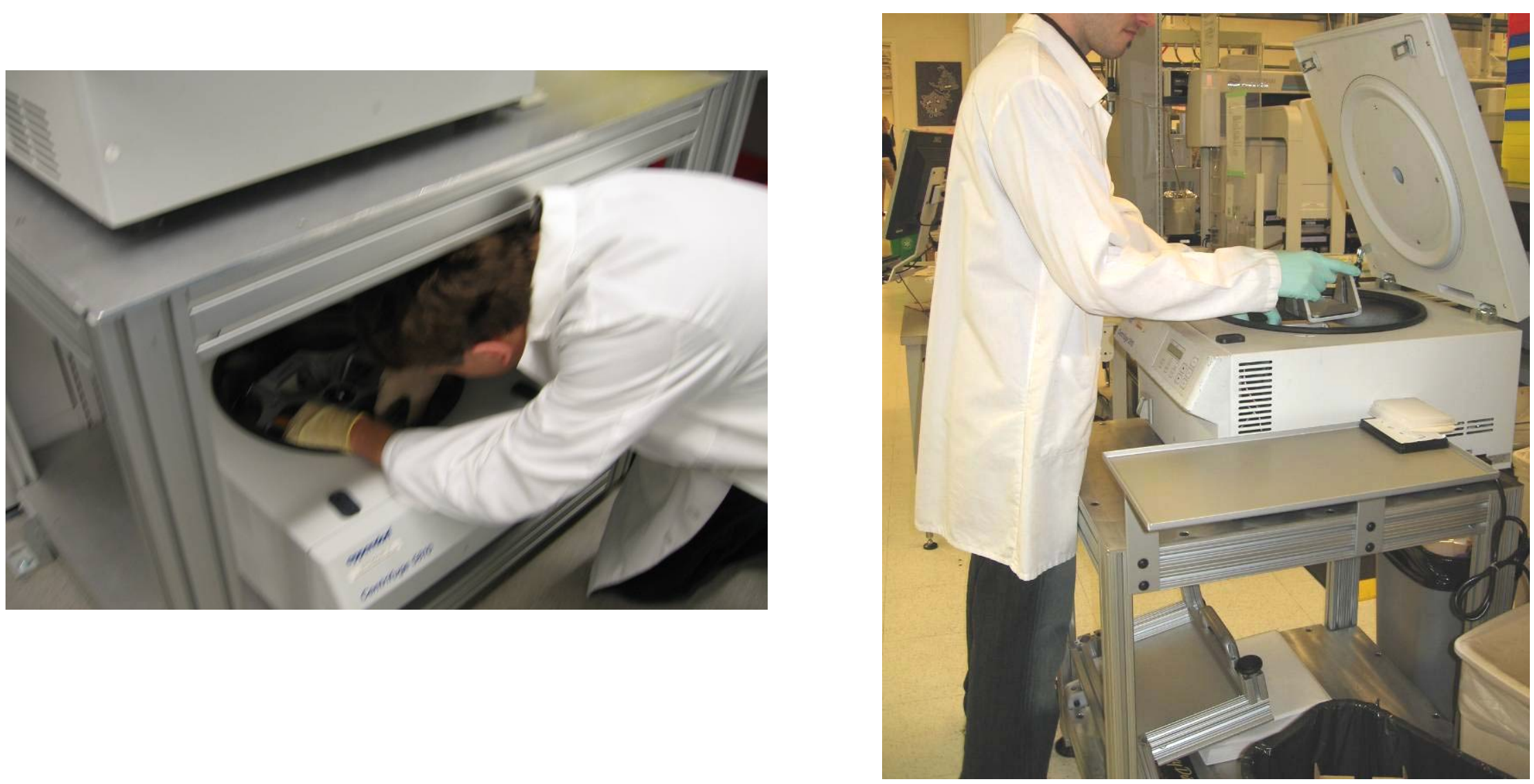


\section{JGIS Production Wide Ergo Improvements}

Best Practices and Training
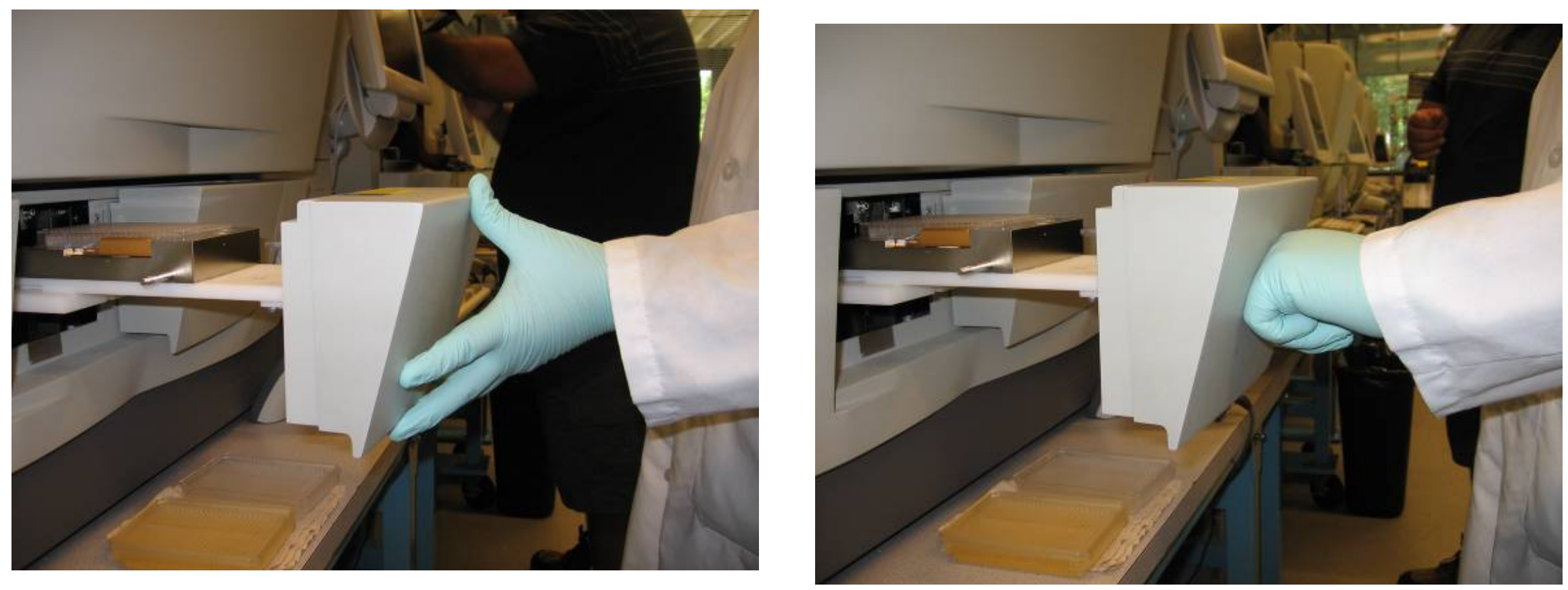

Before

After 


\section{JGI Production Wide Ergo Improvements}

Anti-Fatigue Mats
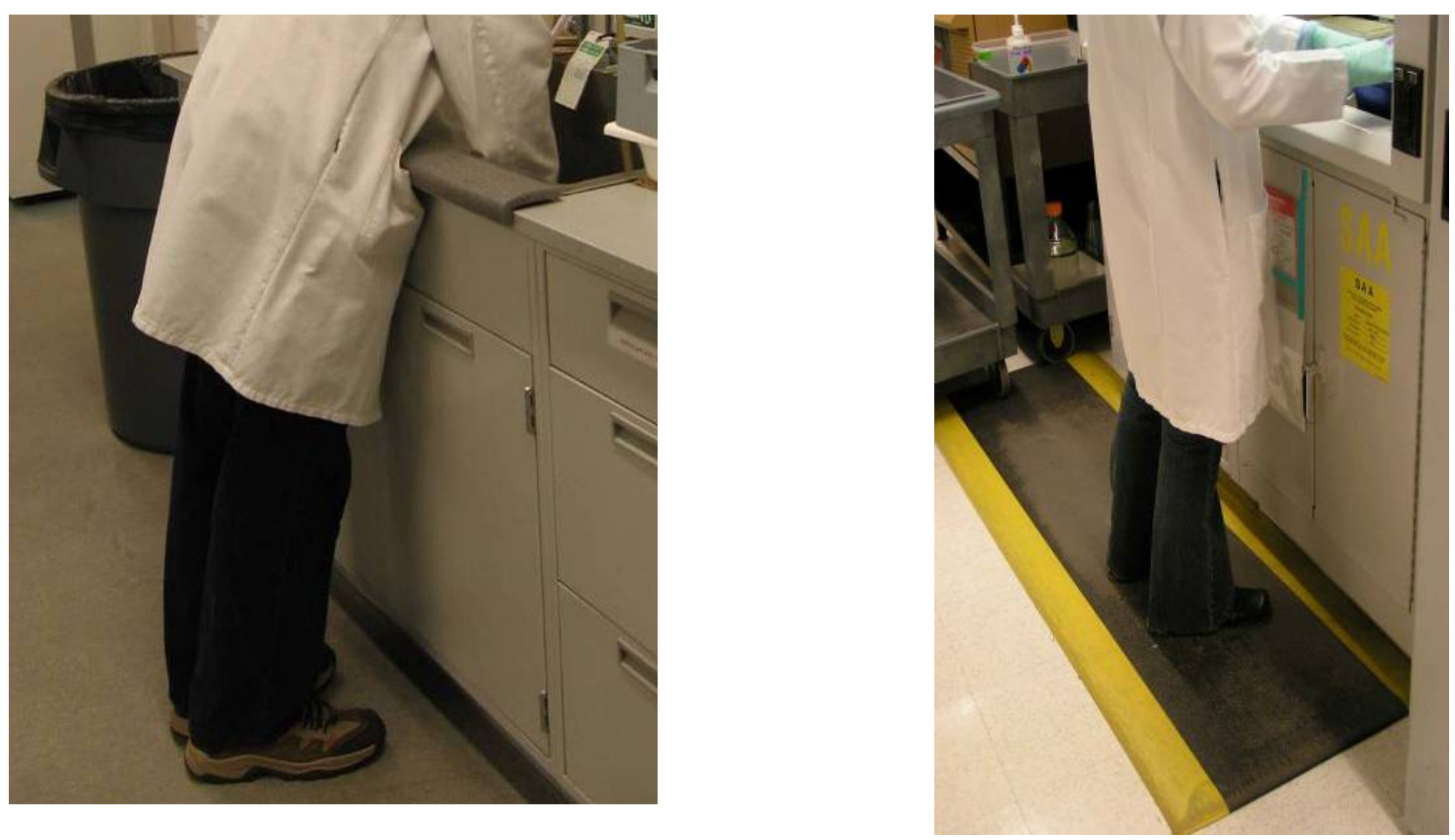

Before

After 


\section{The JGI Ergo Program Why Are We Having Success?}

- Teamwork

- Employee-led Ergonomics Working Group

- Management Commitment

- Identify Solutions

- Quick Fix-Administrative Solutions

- Long Term-Engineering Solutions

- On-Site Ergo Support

- Rapid Response

- Encourage Early Reporting

- Communication/Education

- Group Meetings

- Posters

- Weekly Ergo Email

- Custom Ergo Training Courses 


\section{Communication and Education}

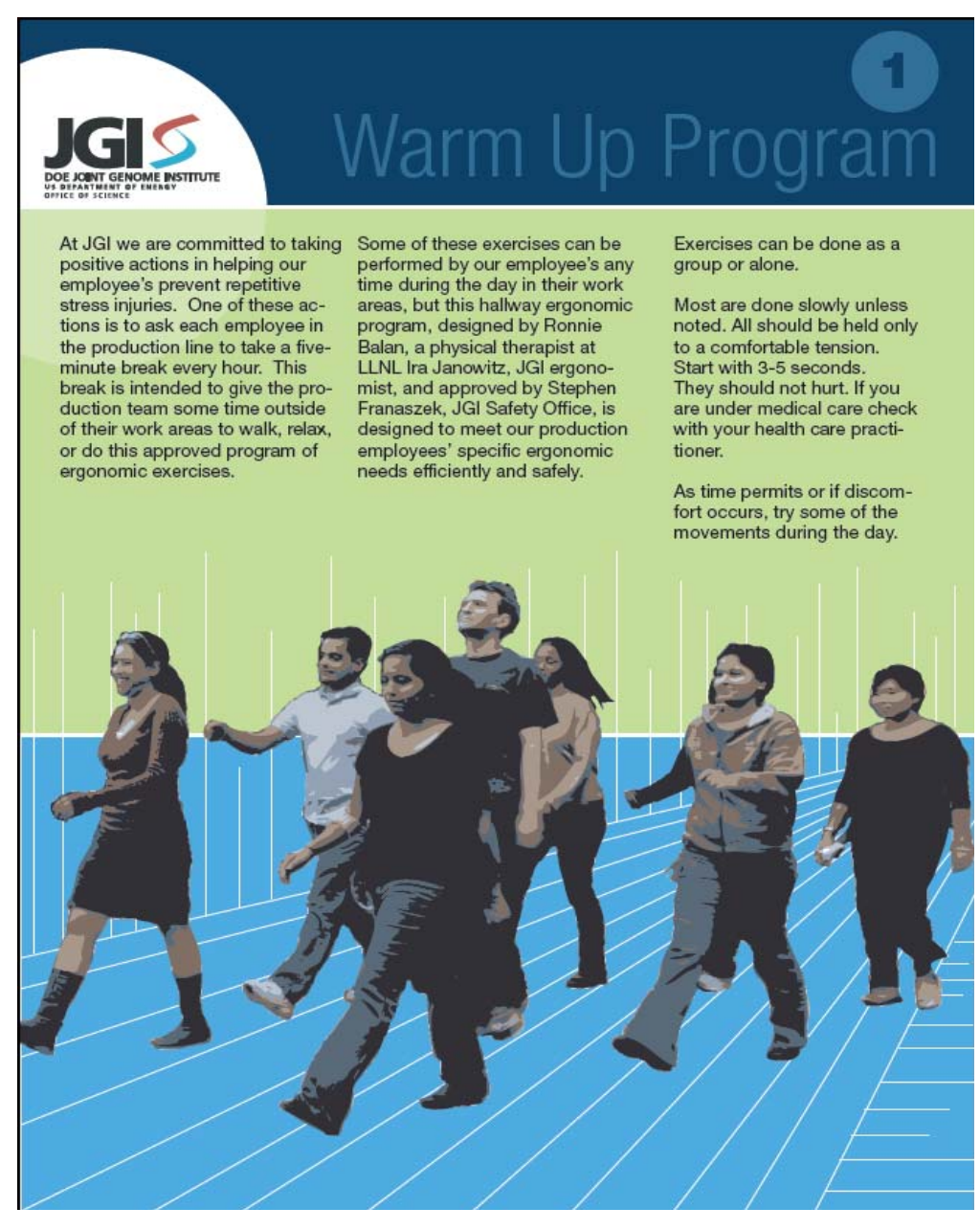

Stretch Posters

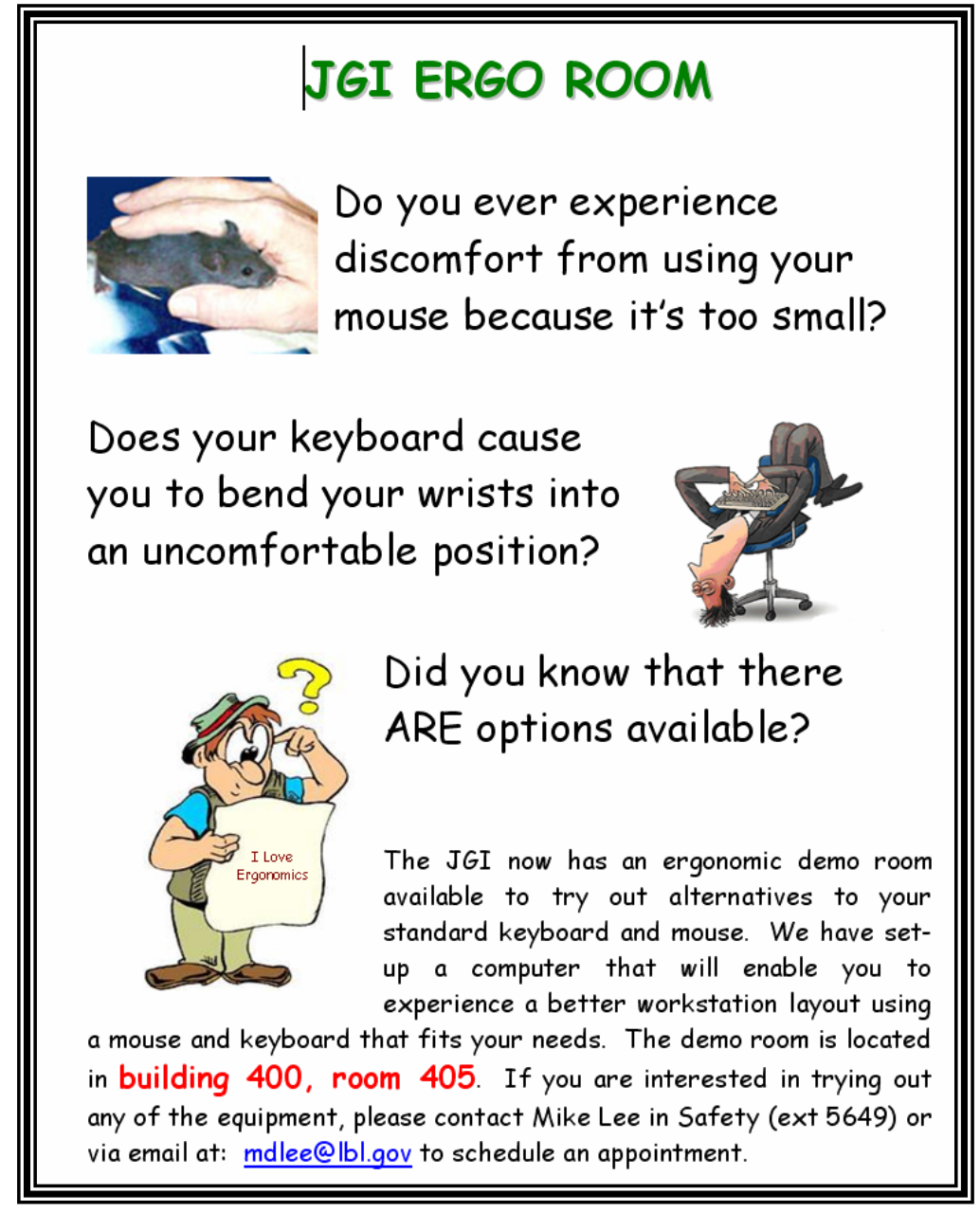

Potty Training 


\section{CY 2006-Current}
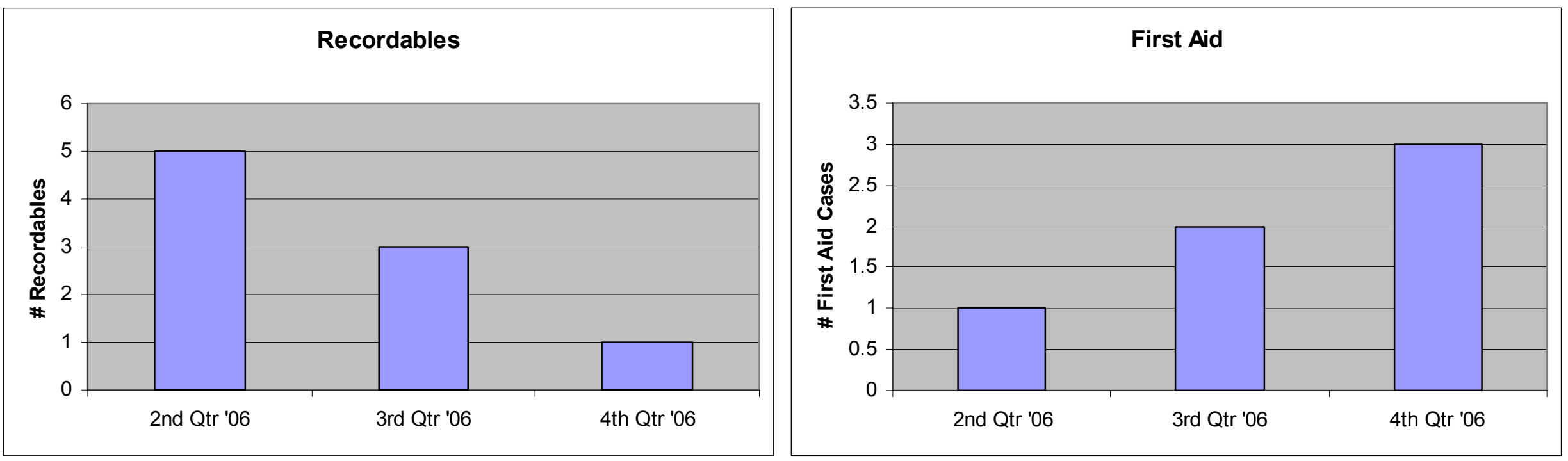


\section{Work Pattern Issues}

- Regular Breaks and Lunch

- Mix of hand-intensive activities

- Overtime practices

- Staffing issues

The production line has been reorganized by shift instead of by work areas. This will better handle staffing shortages and distribute ergonomic risk across different tasks. 


\section{Intel Technology Engagement Model}

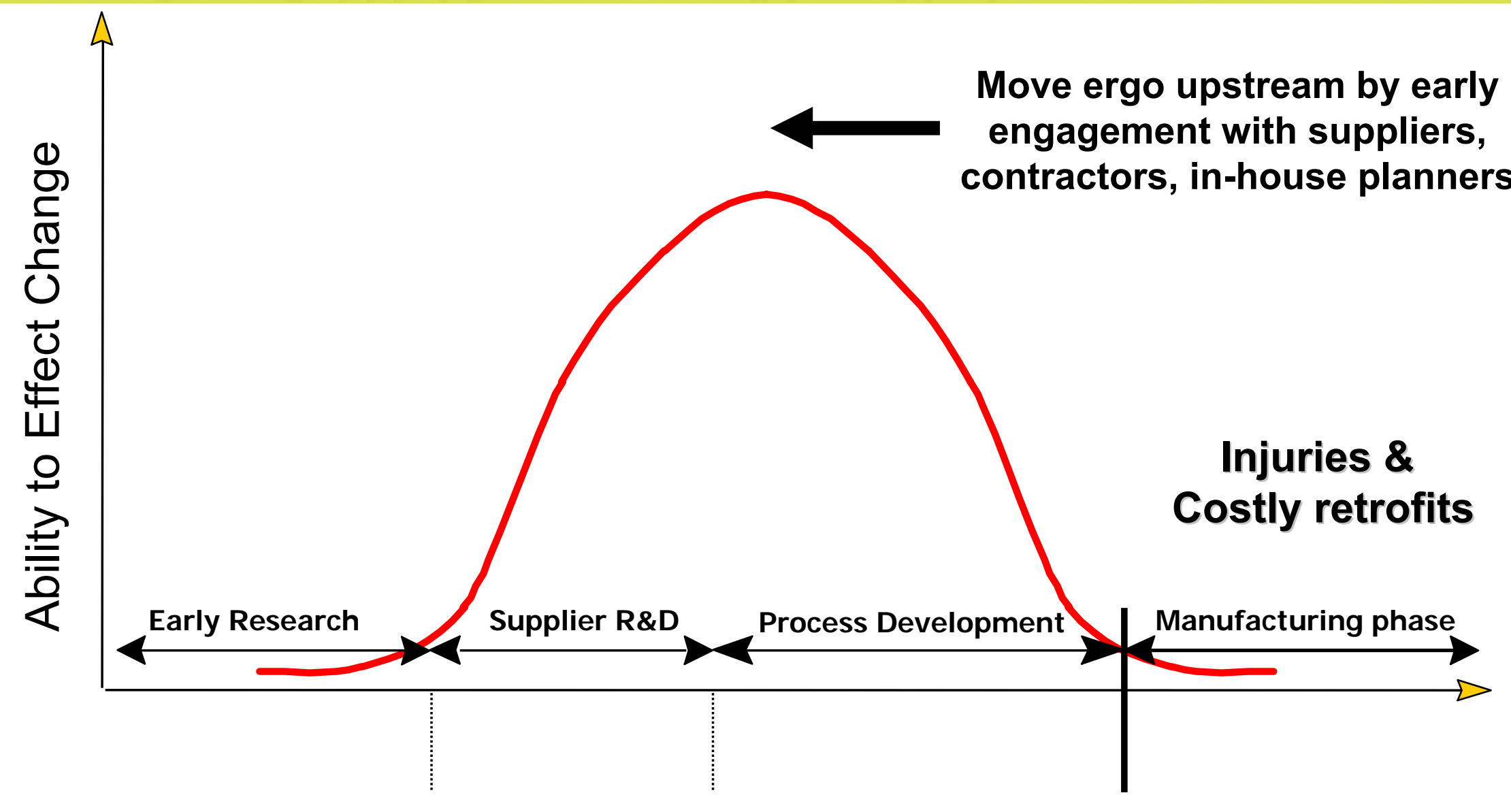

Low to High Volume Increases Ergonomics Problems Need to consider duration, repetitiveness + mix of tasks 

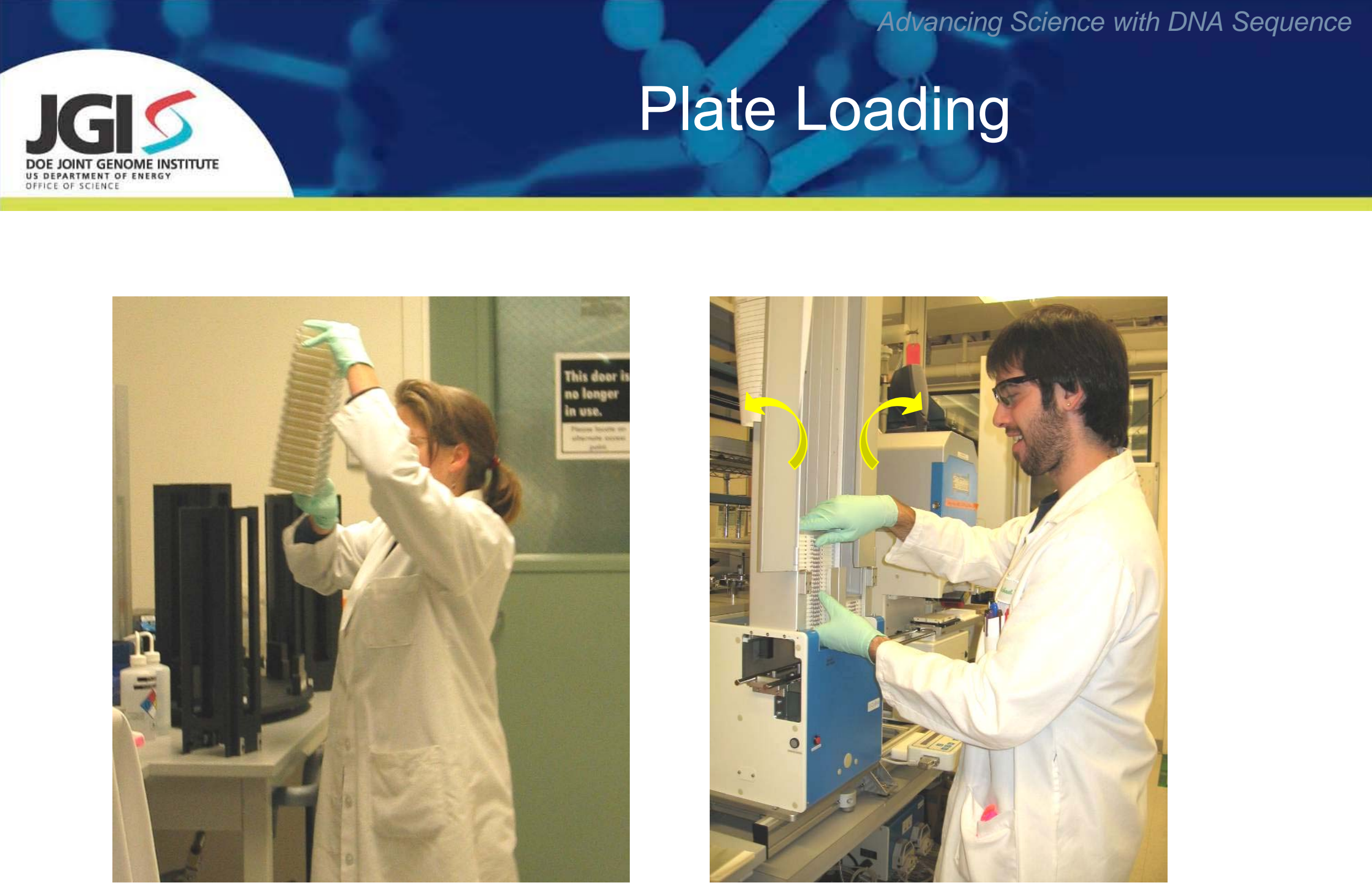


\section{Ergo Evaluation Techniques}

Semiquantitative Assessment Methods

Quantitative Assessment Methods

Moore-Garg Strain Index

-Estimates the risk of injury to the distal upper extremity (elbow and below) -Integrates risk factors: force, repetition, posture, recovery time, and duration of the day 
Moore-Garg Strain Index

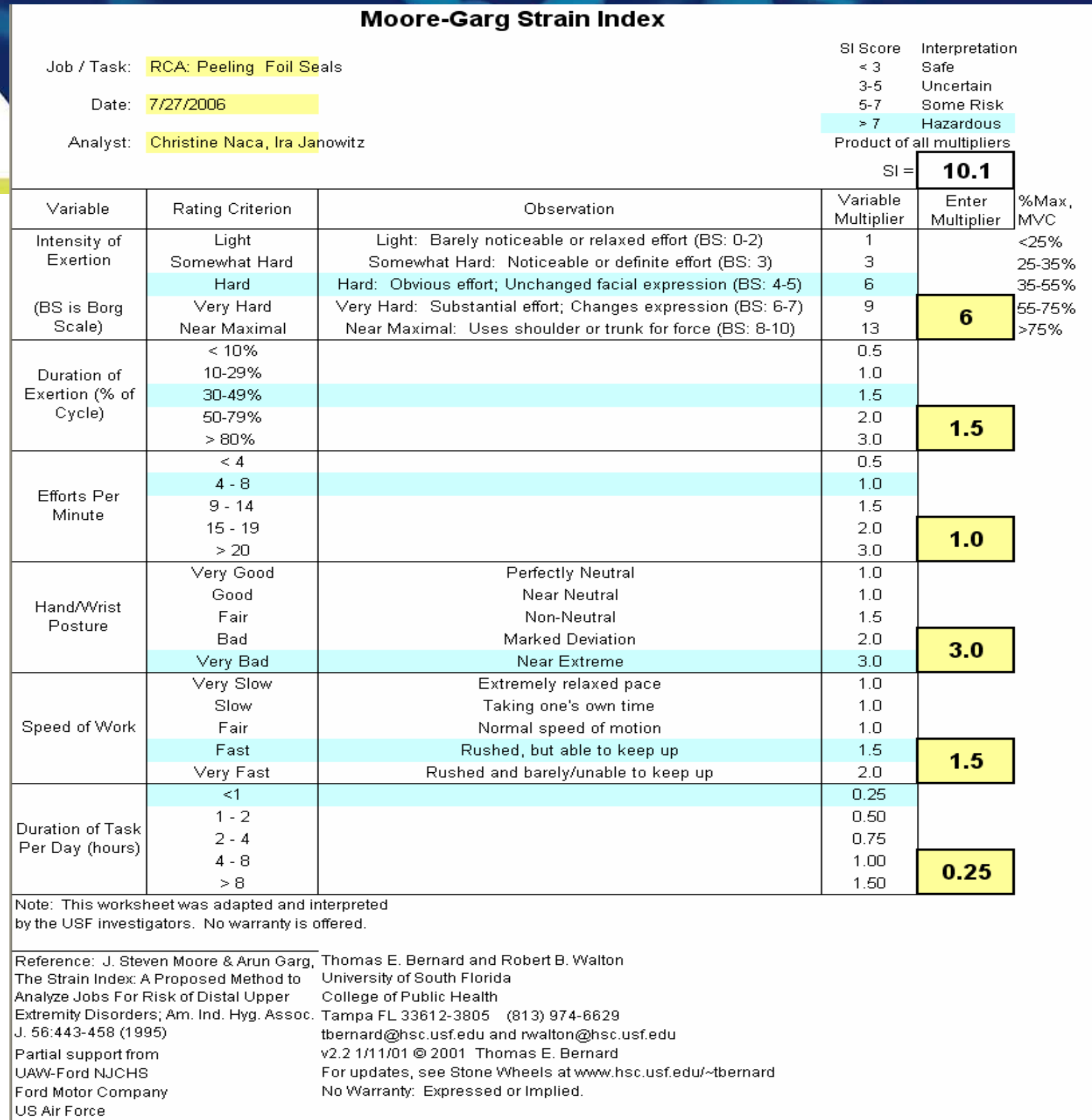




\section{How much is too much?}

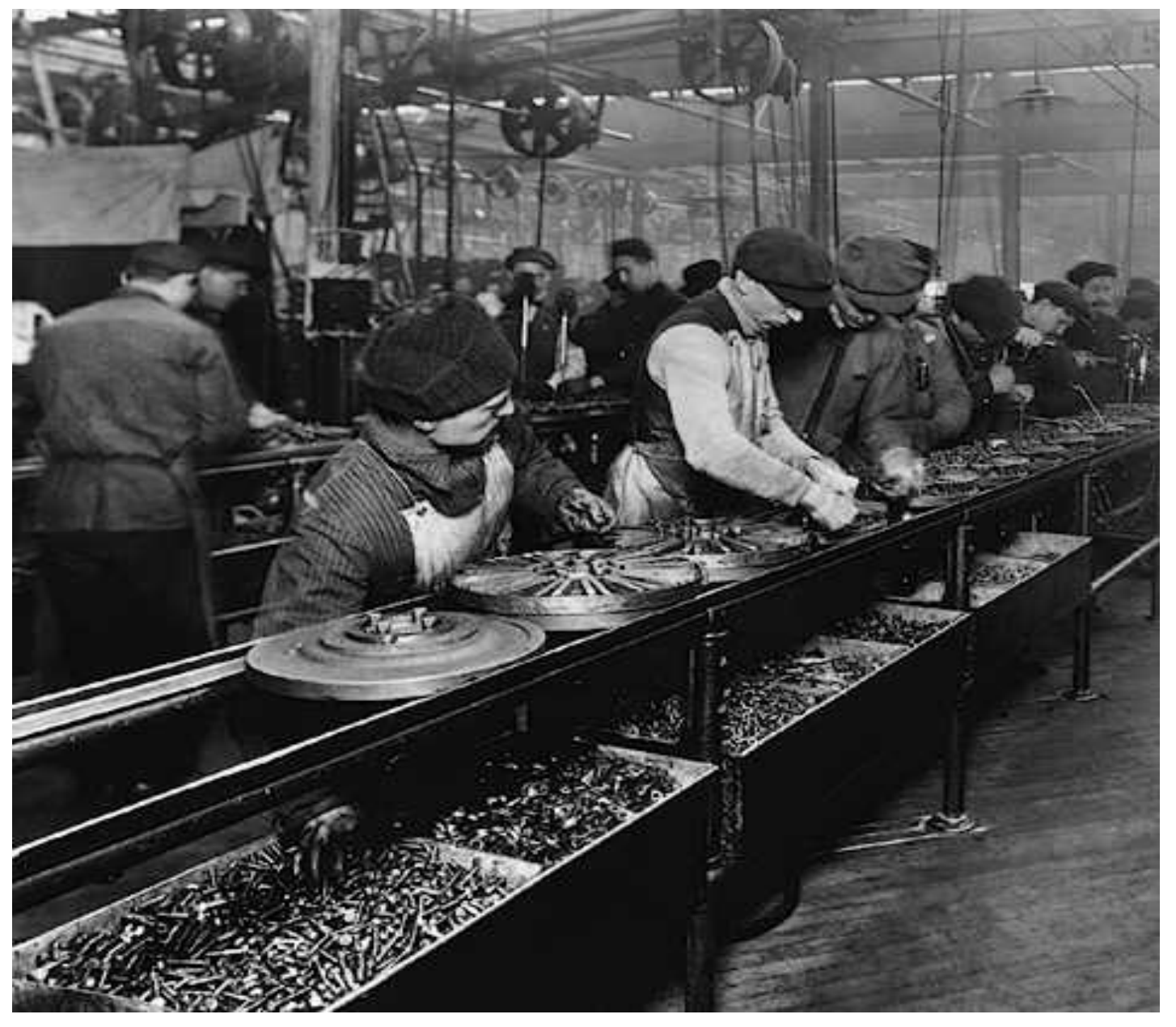




\section{JGI Prodúction Environment}

- Complex, heterogeneous mix of tasks $\rightarrow$ difficult to track and control ergo risk exposure

- Supervisors need guidelines for assigning workload within safe parameters 


\section{In Summary}

- Collaborative Effort

- Continuous Improvement

- Proactive and Participatory Ergonomics Program

Results:

- Improved Employee Morale

- Decreased Recordable Injuries 